\title{
Cost-effectiveness of gefitinib, icotinib, and pemetrexed-based chemotherapy as first-line treatments for advanced non-small cell lung cancer in China
}

\author{
Shun Lu ${ }^{1}$, Ming $\mathrm{Ye}^{2}$, Lieming Ding ${ }^{3}$, Fenlai $\mathrm{Tan}^{3}$, Jie Fu${ }^{4}$, Bin Wu${ }^{4}$ \\ ${ }^{1}$ Department of Medical Oncology, Shanghai Chest Hospital, Shanghai Jiaotong University, Shanghai, China \\ ${ }^{2}$ Department of Radiotherapy, Renji Hospital, School of Medicine, Shanghai Jiaotong University, Shanghai, China \\ ${ }^{3}$ Betta Pharmaceuticals Co., Ltd., Hangzhou, China \\ ${ }^{4}$ Medical Decision and Economic Group, Department of Pharmacy, Renji Hospital, School of Medicine, Shanghai Jiaotong \\ University, Shanghai, China \\ Correspondence to: Bin Wu, email: wbwithtg@hotmail.com \\ Keywords: gefitinib, icotinib, EGFR mutation, cost-effectiveness, non-small cell lung cancer \\ Received: September 20, 2016 \\ Accepted: December 12, 2016 \\ Published: December 27, 2016
}

\section{ABSTRACT}

Tyrosine kinase inhibitors of the epidermal growth factor receptor (EGFR) are becoming the standard treatment option for patients with advanced non-small cell lung cancer (NSCLC) harboring an EGFR mutation, but the economic impact of this practice is unclear, especially in a health resource-limited setting. A decision-analytic model was developed to simulate 21-day patient transitions in a 10-year time horizon. The health and economic outcomes of four first-line strategies (pemetrexed plus cisplatin [PC] alone, PC followed by maintenance with pemetrexed, or initial treatment with gefitinib or icotinib) among patients harboring EGFR mutations were estimated and assessed via indirect comparisons. Costs in the Chinese setting were estimated. The primary outcome was the incremental cost-effectiveness ratio (ICER). Sensitivity analyses were performed. The icotinib strategy resulted in greater health benefits than the other three strategies in NSCLC patients harboring EGFR mutations. Relative to PC alone, PC followed by pemetrexed maintenance, gefitinib and icotinib resulted in ICERs of $\$ 104,657, \$ 28,485$ and $\$ 19,809$ per quality-adjusted life-year gained, respectively. The cost of pemetrexed, the EGFR mutation prevalence and the utility of progression-free survival were factors that had a considerable impact on the model outcomes. When the icotinib Patient Assistance Program was available, the economic outcome of icotinib was more favorable. These results indicate that gene-guided therapy with icotinib might be a more cost-effective treatment option than traditional chemotherapy.

\section{INTRODUCTION}

Lung cancer is the most frequent malignancy and the most common cause of cancer-related death among males and females in the worldwide [1]. Based on the Chinese epidemiological data, the incidence (48.32 per $100,000)$ and mortality rate $(39.27$ per 100,000$)$ of lung cancer in China were also high [2]. The disability-adjusted life years caused by lung cancer were documented in 2013 compared with 1990, especially among males [3]. Nonsmall cell lung cancer (NSCLC) manifests nearly $85 \%$ of all lung cancer cases [4], and about $46 \%$ of NSCLC cases are diagnosed as advanced disease at the time of presention [5]. Platinum-based chemotherapy have been recommended for patients with advanced NSCLC $[6,7]$. However, clinical outcomes of chemotherapy is still poor, which showed the median overall survival (OS) time is approximately 10 months.

Small-molecule tyrosine kinase inhibitors (TKIs), such as erlotinib, gefitinib and afatinib, could specifically inhibit epidermal growth factor receptor (EGFR)-dependent pathway activity, could prolong OS and/or progression-free survival (PFS) in patients with advanced NSCLC and harboring an EGFR mutation [8,9]. Thus, these EGFR-specific TKIs have been recommended in guidelines since 2010 for patients with newly diagnosed advanced NSCLC and harboring an EGFR 
mutation [6, 10]. Recently, icotinib, a novel EGFR-specific TKI originally developed in China, has been licensed for managing the Chinese newly diagnosed advanced NSCLC based on two large phase III randomized controlled trials (RCTs) $[11,12]$. Owing to the lower cost, superior toxicity profile and equivalent efficacy of icotinib in comparison with erlotinib and gefitinib, icotinib appears to be a better alternative for Chinese patients with advanced NSCLC [12, 13]. However, utilizing both EGFR-specific TKIs may add a financial burden, especially when considering the cost of genetic screening in addition to the cost of the agents. Hence, it is necessary for health decision-makers, patients and physicians to determine the relative value of these potential first-line therapies. This study seeks to compare the economic outcomes of gene-guided first-line icotinib and gefitinib treatment with those of pemetrexed-containing chemotherapy for advanced NSCLC in the Chinese health care setting.

\section{RESULTS}

\section{Base-case analysis}

Compared to the control strategy (Table 1), the pemetrexed maintenance strategy, the gefitinib strategy, and the icotinib strategy yielded marginal QALYs of $0.094,0.003$ and 0.023 , respectively. As the baseline comparator, the control strategy was the least expensive strategy. The pemetrexed maintenance, gefitinib, and icotinib strategies added costs of $\$ 9,519, \$ 2,010$, and

Cost of pemetrexed per 500mg

EGFR prevelance

Utility of PFS

Cost of EGFR mutation testing

Cost of icotinib per day

HR of PFS of icotinib

21-days cycles of 1st-line PC chemotherapy

Cost of the chemotherapy excluding the non-platinum agents/21-day cycle

Cost of palliative care in end-of-life
$\$ 1,862$, respectively, relative to the control strategy, resulting in ICERs of $\$ 104,657, \$ 28,485$, and $\$ 19,809$ per QALY gained, respectively. When the PAP for icotinib and gefitinib became available, the ICERs for the icotinib and gefitinib strategies became to $\$ 15,451$ and $\$ 22,577$ per QALY gained, respectively.

\section{Uncertainty analyses}

In the comparison between the icotinib and control strategies, the most influential variables were the cost of pemetrexed, the EGFR prevalence and the utility of PFS. Altering these parameters might yield substantial changes in the ICER (Figure 1). Other parameters, such as the cost of EGFR mutation screening and the HR of PFS of the icotinib versus the control strategy had a moderate or mild impact on economic outcomes.

The CEACs are showed in Figure 2. Regardless of the availability of the PAP, the icotinib strategy showed cost-effectiveness in approximately $90 \%$ of the simulations, considering a cost-effectiveness threshold of $\$ 22,200$ (3× the Chinese per capita GDP in 2015).

\section{DISCUSSION}

This study to firstly examine the cost-effectiveness of four licensed competing first-line treatment options recommended in current Chinese clinical practice [12], and our results are of great significance in this health

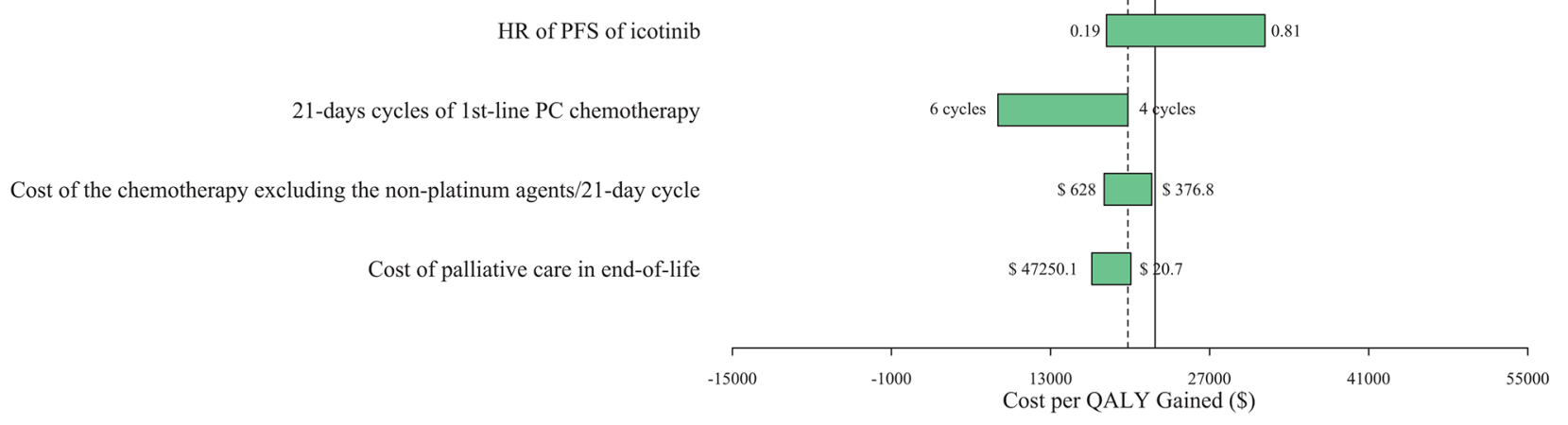

Figure 1: One-way sensitivity analyses for EGFR testing in combination with icotinib treatment in comparison with PC chemotherapy. PC: pemetrexed plus cisplatin. 
Table 1: Summary of Cost (\$) and Outcome Results in base-case analysis

\begin{tabular}{lcccccc}
\hline Strategy & Cost & $\begin{array}{c}\text { Progression-free } \\
\text { LYs }\end{array}$ & Overall LYs & QALYs & $\begin{array}{c}\text { Incremental } \\
\text { cost per QALY* }\end{array}$ & Comments \\
\hline PC (control strategy) & 22,127 & 0.206 & 1.058 & 0.513 & NA & \\
$\begin{array}{l}\text { Pemetrexed maintenance } \\
\text { strategy }\end{array}$ & 31,646 & 0.300 & 1.208 & 0.604 & 104,657 & Dominated \\
Gefitinib strategy & 24,137 & 0.279 & 1.165 & 0.584 & 28,485 & Dominated \\
Icotinib strategy & 23,989 & 0.303 & 1.202 & 0.607 & 19,809 & Dominance \\
Gefitinib strategy with & 23,721 & 0.279 & 1.165 & 0.584 & 22,577 & Dominated \\
PAP & & 0.303 & 1.202 & 0.607 & 15,451 & Dominance \\
Icotinib strategy with PAP & 23,580 & & & & &
\end{tabular}

* Comparing with Control strategy

resource-limited setting. The main finding of the current analysis was that icotinib for treating newly diagnosed advanced NSCLC and harboring an EGFR mutation provides better health outcomes than other therapies. The main finding suggested that the ICER of the icotinib strategy was lower than the ICERs of the pemetrexed maintenance and gefitinib strategies. Icotinib was found to be the most cost-effective therapeutic approach. The PSA found that the highest probability of cost-effectiveness of icotinib would be achieved at a threshold of $\$ 22,200$. These findings are generally coherent with previous published studies that reported the economic outcomes of TKIs (gefitinib, afatinib and erlotinib) as first-line managements for advanced NSCLC [14-16].

In the study from Japan, the marginal cost and effectiveness of the screening strategy (EGFR mutation testing followed by gefitinib treatment) per patient were estimated to be approximately $\$ 1,180$ and 0.036 QALYs,
A.

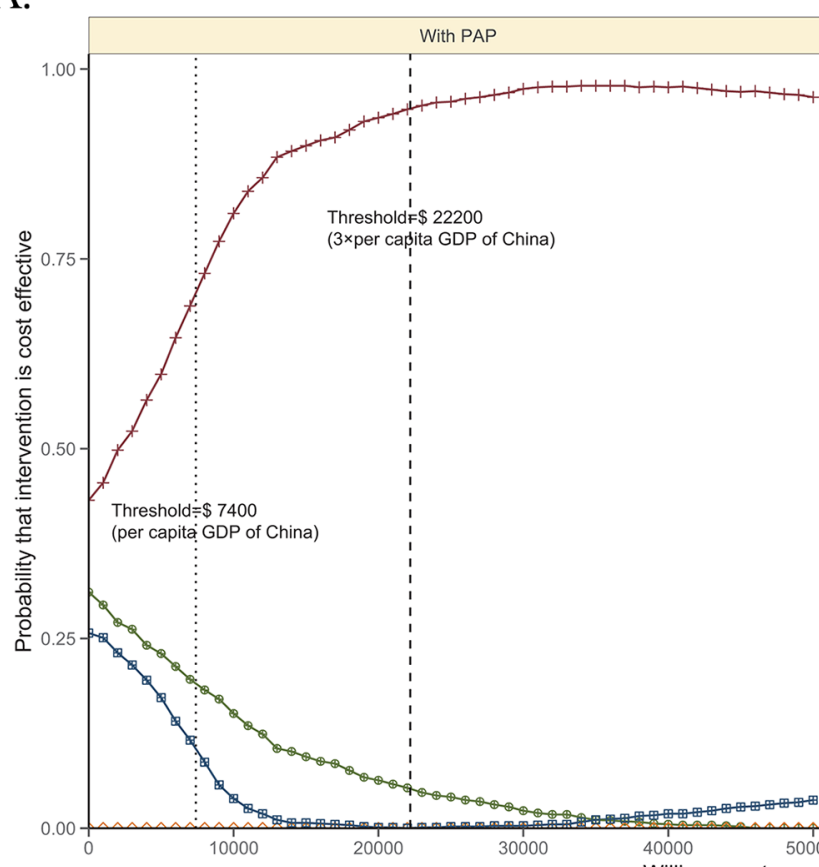

B.

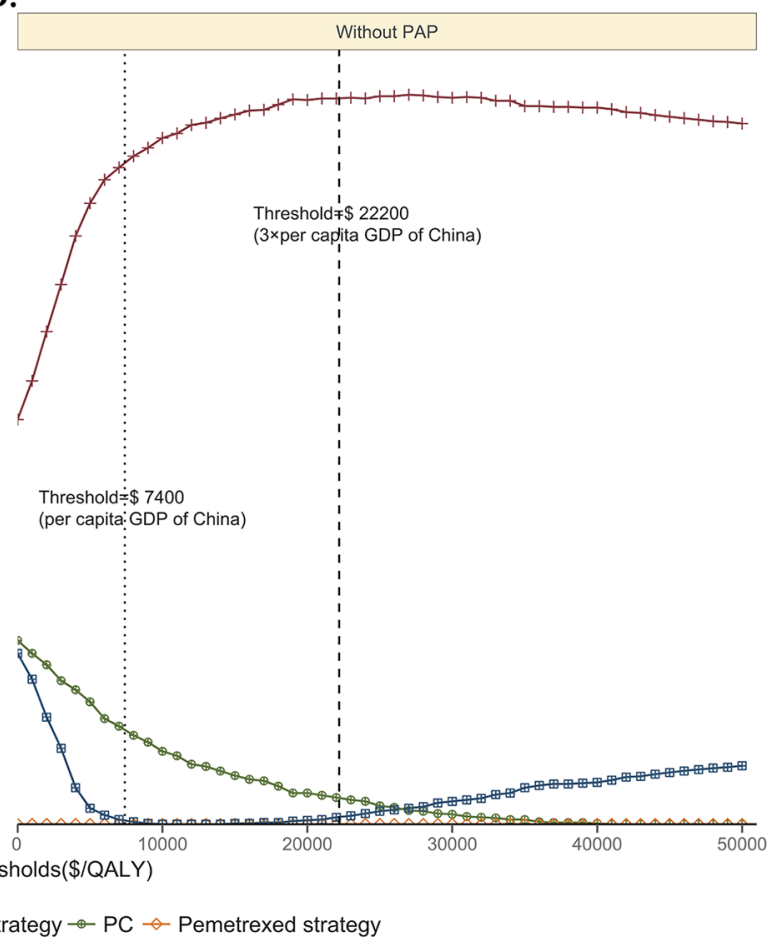

Figure 2: Acceptability curves comparing the cost-effectiveness of four competing strategies with the PAP A. or without the PAP B. QALY: quality-adjusted life-year. PC: pemetrexed plus cisplatin. 
respectively, leading to a marginal cost of $\$ 32,500$ per additional QALY gained. These findings demonstrated that the EGFR screening strategy in Japan is cost-effective [15]. By using a decision-analytic model, one Singaporean study evaluated the economic outcome of gefitinib treatment for advanced NSCLC patients with activating EGFR mutations, which showed EGFR testing combined with first-line gefitinib treatment was a superior strategy to standard care due to lower costs and greater health benefits [17].
Our study also found that the icotinib strategy was less expensive than the pemetrexed maintenance and gefitinib strategies, which were inferior owing to their smaller health benefits and higher costs. One plausible explanation for this finding is that the cost per cycle of the icotinib strategy was lower than that of the pemetrexed maintenance and gefitinib strategies. One recently published study of second-line treatment for advanced NSCLC showed 5-year QALYs of 0.279 and 0.269 and medical costs of $\$ 10,662.82$ and $\$ 13,127.57$ in the

A.

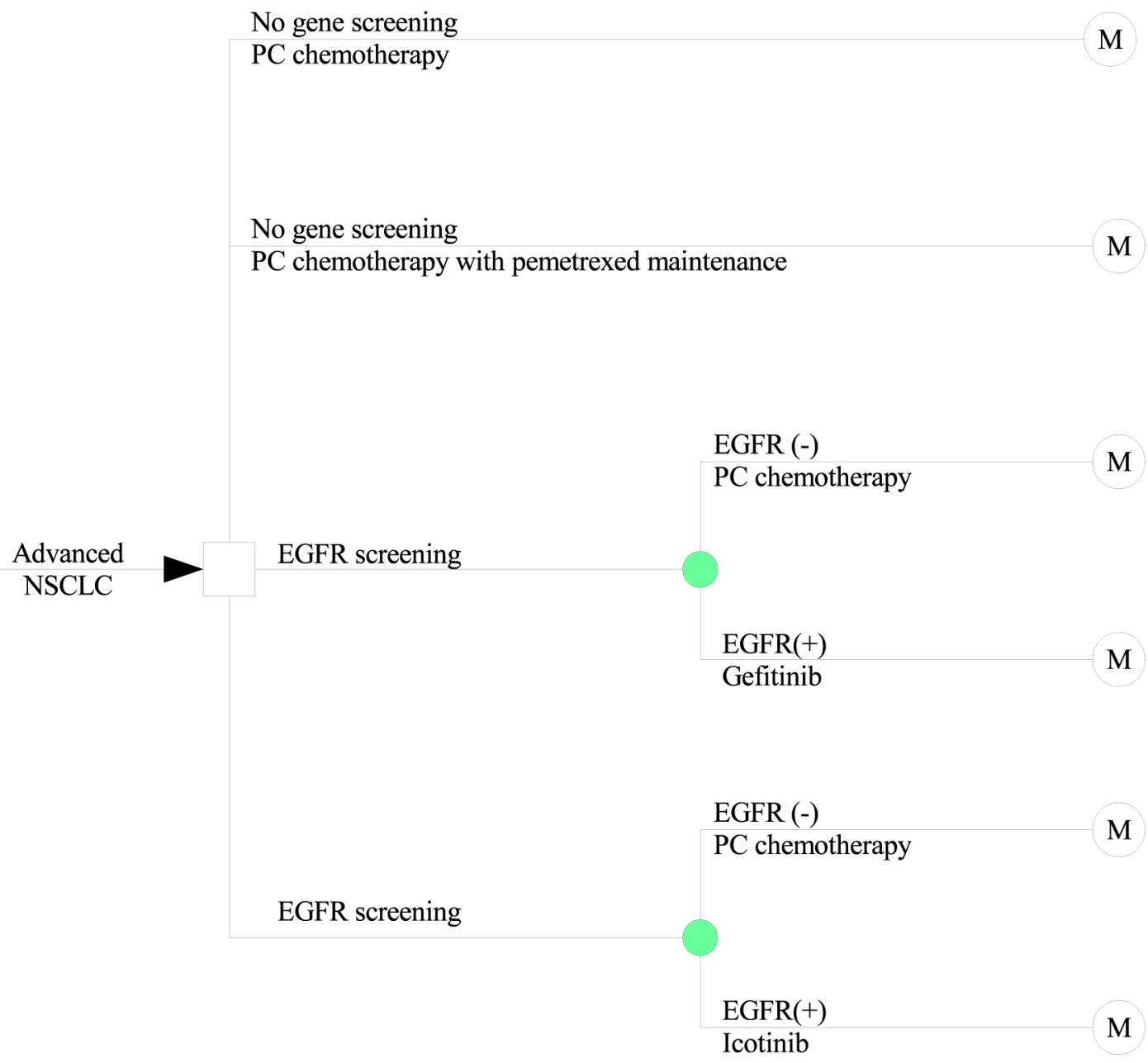

B.

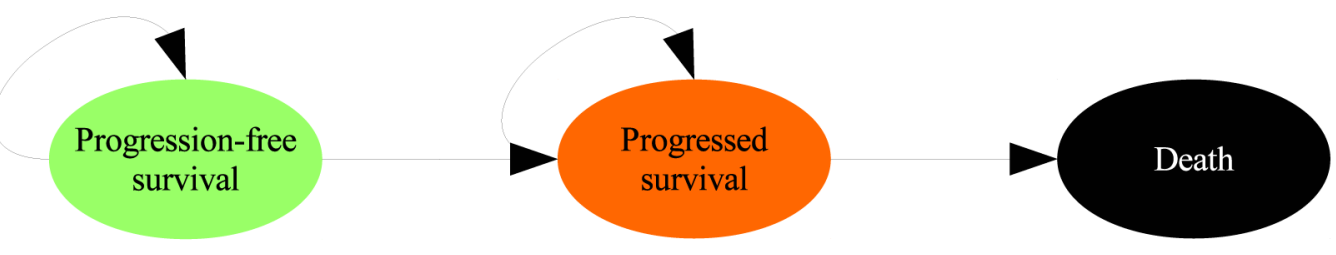

Figure 3: Schematics of the decision tree A. and the Markov state transition model B. NSCLC: non-small cell lung cancer; EGFR: epidermal growth factor receptor. 
Table 2: Key clinical data

\begin{tabular}{lccc}
\hline Parameter & Expected Values (Ranges) & Distribution (Parameters) & Description and Reference \\
\hline $\begin{array}{l}\text { Weibull survival model of } \\
\text { PFS for PC }\end{array}$ & $\begin{array}{c}\text { Scale }=0.1029 ; \text { Shape } \\
1.3077 ; \mathrm{r}^{2}=0.981\end{array}$ & NA & [24] \\
$\begin{array}{l}\text { HR of PFS for PC followed } \\
\text { by pemetrexed maintenance }\end{array}$ & 0.59 & Normal $(0.59,0.161)$ & Network meta-analysis \\
$\begin{array}{l}\text { HR of PFS for gefitinib } \\
\text { HR of PFS for icotinib }\end{array}$ & $0.48(0.29-0.8)$ & Normal $(0.48,0.13)$ & Network meta-analysis \\
$\begin{array}{l}\text { Probability of survival after } \\
\text { progression }\end{array}$ & $0.4(0.19-0.81)$ & Normal $(0.4,0.158)$ & Network meta-analysis \\
$\begin{array}{l}\text { EGFR mutation prevalence } \\
\text { Probability of SAEs from the } \\
\text { control strategy }\end{array}$ & $0.456(0.342-0.57)$ & Beta $(751.1,7982.7)$ & {$[33]$} \\
$\begin{array}{l}\text { Probability of SAEs from the } \\
\text { pemetrexed strategy }\end{array}$ & $0.637(0.478-0.796)$ & Normal $(0.47,0.143)$ & {$[34]$} \\
$\begin{array}{l}\text { Probability of SAEs from the } \\
\text { gefitinib strategy }\end{array}$ & $0.1(0.075-0.125)$ & Beta $(33.6,40.1)$ & {$[24,35]$} \\
$\begin{array}{l}\text { Probability of SAEs from the } \\
\text { icotinib strategy }\end{array}$ & $0.07(0.053-0.088)$ & Beta $(53.3,479.3)$ & {$[24]$} \\
Body surface area (m $\left.{ }^{2}\right)$ & $1.72(1.5-1.9)$ & Beta $(56.3,747.4)$ & {$[36]$} \\
\hline
\end{tabular}

PC: pemetrexed plus cisplatin; EGFR: epidermal growth factor receptor; SAEs: serious adverse events ( $\geq$ grade 3); PFS: progression-free survival; HR: hazard ratio; NA: not applicable.

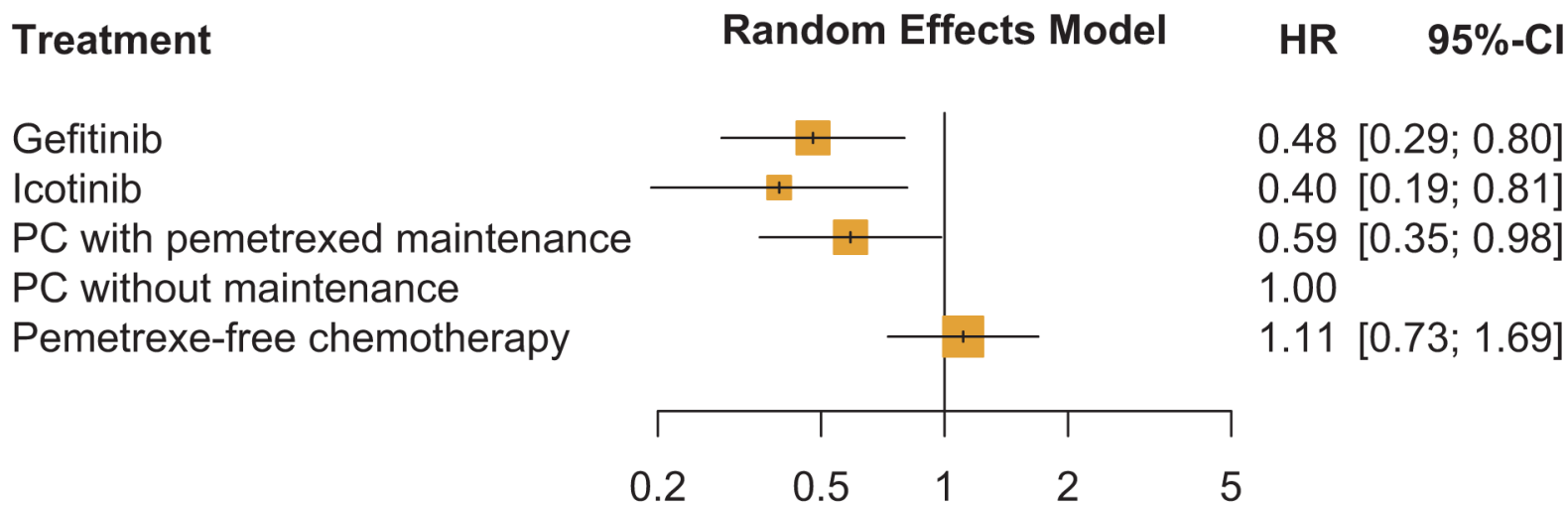

Favour other therapy Favour PC without maintenance

Figure 4: Random-effects network meta-analysis results for PFS of interest using a binomial logit model. PC: pemetrexed plus cisplatin. 
Table 3: Base-Case Costs Estimates and Utilities

\begin{tabular}{|c|c|c|c|}
\hline Parameter & Expected Values (Ranges) & Distribution (Parameters) & Description and Reference \\
\hline \multicolumn{4}{|l|}{ Costs (US \$) } \\
\hline $\begin{array}{l}\text { Cost of pemetrexed per } \\
500 \mathrm{mg}\end{array}$ & $967.57(533.02-2126.51)$ & Gamma $(2303,0.42)$ & [43] \\
\hline $\begin{array}{l}\text { Cost of the chemotherapy } \\
\text { excluding the non-platinum } \\
\text { agents per } 21 \text {-day cycle }\end{array}$ & $518.4(388.8-648)$ & Gamma $(4064.3,0.13)$ & [43] \\
\hline Cost of icotinib per day & $31.72(15.86-31.72)$ & Gamma $(248.7,0.13)$ & Local charge \\
\hline Cost of gefitinib per day & $37.43(18.71-37.43)$ & Gamma $(293.4,0.13)$ & Local charge \\
\hline Cost of follow-up per unit & $55.6(41.7-69.4)$ & Gamma $(437.5,0.13)$ & [43] \\
\hline $\begin{array}{l}\text { Cost of salvage } \\
\text { chemotherapy per cycle }\end{array}$ & $2352.7(1921.1-4383.3)$ & Gamma $(8812.4,0.27)$ & [43] \\
\hline $\begin{array}{l}\text { Cost of palliative care in } \\
\text { end-of-life }\end{array}$ & $2042.91(793.65-5456.19)$ & Gamma $(3508.8,0.58)$ & [43] \\
\hline $\begin{array}{l}\text { Cost of supportive care per } \\
\text { cycle }\end{array}$ & $337.5(158.7-793.7)$ & Gamma $(703.2,0.48)$ & [43] \\
\hline Cost of SAEs per unit & $507.4(189.7-825.0))$ & Gamma $(1588.6,0.32)$ & [43] \\
\hline $\begin{array}{l}\text { Cost of EGFR mutation } \\
\text { testing }\end{array}$ & $380.95(158.73-476.19)$ & Gamma $(1792,0.21)$ & Local charge \\
\hline \multicolumn{4}{|l|}{ Utilities } \\
\hline Utility of PFS & $0.82(0.78-0.86)$ & Beta $(373.6,82)$ & {$[44,45]$} \\
\hline Utility of OS & $0.58(0.5-0.66)$ & Beta $(84,60.9)$ & {$[44,45]$} \\
\hline Disutility of SAEs & $0.35(0.31-0.39)$ & Beta $(199.1,369.7)$ & [44] \\
\hline
\end{tabular}

EGFR: epidermal growth factor receptor; SAEs: serious adverse events ( $\geq$ grade 3); PFS: progression-free survival; OS: overall survival.

icotinib and gefitinib groups, respectively, suggesting that icotinib was a less expensive strategy than gefitinib [18]. Consistent with our study, that previous study also found that the utility of PFS was a sensitive parameter.

This study has several limitations. First, owing to no clinical data evaluating these four first-line alternatives in one trial, a network meta-analysis was performed in the present study for an indirect comparison, where the patient characteristics were assumed to be similar although the moderate heterogeneity was detected. Second, a Weibull survival model was used to simulate the lifetime outcomes. This approach was another limitation of this study, although the results of the sensitivity analysis suggested that the model outcome was not sensitive to the variables related to HR of PFS. Third, some key clinical inputs, such as the survival data for the gefitinib and pemetrexed maintenance strategies, were extracted from distinct RCTs with different study designs conducted on the Western population. To minimize potential bias and uncertainty in outcomes, we tested the impact using sensitivity analyses. Fourth, the current analysis did not fully examine other potentially competing alternatives for advanced NSCLC, such as afatinib, erlotinib and bevacizumab [19-22], because these agents are not currently licensed as firstline treatments in China. Finally, the utility data was not Chinese-specific, which might lead to bias in the model outcomes. However, the sensitivity analyses showed only minor impacts of utility.

In summary, from the perspective of Chinese health care system, gene-guided icotinib therapy for newly diagnosed advanced NSCLC harboring EGFR mutations is a cost-effective alternative relative to chemotherapy containing pemetrexed and gefitinib, based on the higher efficacy and lower cost of icotinib treatment.

\section{MATERIALS AND METHODS}

\section{Analytical overview and model structure}

A mathematical model was constructed to measure the ten-year clinical and economic outcomes of firstline treatments for patients with advanced NSCLC. 
A hypothetical cohort with confirmed stage IIIb or IV NSCLC and positive for an EGFR mutation was created to compare four potential competing strategies: fourcycle chemotherapy based on pemetrexed plus cisplatin (PC) (control strategy), PC chemotherapy followed by maintenance with pemetrexed (pemetrexed strategy) or initial targeted treatment with gefitinib (gefitinib strategy) or icotinib (icotinib strategy) (Figure 3A). After the disease progressed, salvage chemotherapy or supportive care was administered. Health and economic outcomes were projected using a Markov process (Figure 3B) considering three exclusive health states: PFS, survival after progression and death. The Markov cycle length was 21 days, and the initial health state for all patients was PFS. The risk of disease progression or death was determined based on the published literature. Owing to the good tolerability of pemetrexed, gefitinib and icotinib [23-25], this hypothetical analysis did not consider the impact of tolerability to simplify the model.

The primary outcomes were disease-free life years (LYs), overall LYs, quality-adjusted life-years (QALYs) and cost. Cost and QALYs were discounted at an annual rate of $5 \%$, in line with Chinese guidelines for pharmacoeconomic evaluations. The costs are shown in 2015 US dollars. Incremental cost-effectiveness ratios (ICERs), presented as cost per additional QALY gained, were examined. We used $3 \times$ the per capita gross domestic product (GDP) of China in 2015 (US \$22,200) as the cost-effectiveness threshold according to the WHO recommendations.

\section{Clinical data}

The transition parameters and proportions were based on meta-analyses or RCTs to the greatest possible extent. The PARAMOUNT trial reported the efficacy of pemetrexed maintenance therapy after PC-based induction chemotherapy in patients with non-squamous NSCLC. The results showed a median PFS time of 6.9 months for the pemetrexed group and 5.6 months for the placebo group (HR $0.59,95 \%$ CI $0.47-0.74$ ); in that study, PFS was measured from the beginning of induction treatment (rather than from the time of randomization) [24]. The CONVINCE trial compared first-line icotinib therapy to PC followed by maintenance therapy with pemetrexed in lung adenocarcinoma patients harboring a sensitizing EGFR mutation; the results of that trial showed that the icotinib therapy significantly prolonged PFS compared with the chemotherapy (296 days vs 219 days; HR 0.67, $95 \%$ CI $0.49-0.90, p=0.008$ ) [23]. The IPASS trial demonstrated the superiority of gefitinib to traditional (pemetrexed-free) chemotherapy in terms of PFS in patients harboring EGFR mutations (HR 0.48, 95\% CI 0.36-0.64). The subsequent NEJ002 and WJTOG3405 trials, which included only patients harboring EGFR mutations, further confirmed that gefitinib is superior to (pemetrexed-free) chemotherapy in terms of PFS (HR $0.30,95 \%$ CI $0.22-0.41$ in the NEJ002 trial, and HR 0.49, 95\% CI 0.33-0.71 in the WJTOG3405 trial) in patients harboring EGFR mutations [25-27]. One meta-analysis reported that the HR of PFS for pemetrexed plus platinum doublet chemotherapy relative to platinum plus another first-line chemotherapy agent as a first-line treatment for advanced non-squamous NSCLC patients was 0.90 (95\% CI 0.80-1.01) [28].

Indirect comparisons of the four strategies were conducted using the survival rate for PC chemotherapy (control strategy) from the reports of the PARAMOUNT trial as the reference [24]. Weibull survival models were fitted to the Kaplan-Meier curves of PFS for the control strategy according to data from the reports of the PARAMOUNT trial. The estimated Weibull scale $(\lambda)$ and shape $(\gamma)$ parameters are shown in Table 2. The survival probability at time $t$ was calculated using the following formula: $S(t)=\mathrm{P}(T \geq t)=\exp \left(-\lambda t^{\prime}\right)$. The transition probability at a given cycle $t$ was calculated using the following formula: $\mathrm{P}(t)=1-\exp \left[\lambda(t-1)^{y}-\right.$ $\left.\lambda t^{\prime}\right]$. The Weibull survival curves of the three alternative strategies were derived using the adjusted Weibull scale $\left(\lambda_{\text {alternative strategy }}=\lambda_{\text {control strategy }} \times H R_{\text {network meta-analysis }}\right)$ and shape $\left(\gamma_{\text {alternative strategy }}=\gamma_{\text {control strategy }}\right)$ parameters, as previously described in published studies [29, 30]. However, given the absence of head-to-head clinical trial data, the HRs of PFS for the gefitinib and icotinib strategies relative to the control strategy considered in the economic model were generated using network meta-analysis based on a random-effects model because of the heterogeneity $\left(I^{2}=64.1 \%\right)$. As showed in Figure 4, this network meta-analyses was performed with a graph-theoretical methodology implemented in the $\mathrm{R}$ package netmeta $[31,32]$. The HRs of PFS from each clinical trial were derived from the previously mentioned published studies. Table S1 in Appendix summarized the characteristics of all involved studies.

The probability of survival after progression was derived from a published study [33], which identified 69 trials of first-line chemotherapy for advanced NSCLC and which found that the median survival time after disease progression was 5.4 months. The EGFR mutation frequency among NSCLC patients in the Asia-Pacific region was $47 \%(20 \%-76 \%)$ [34].

\section{Cost and utility data}

This analysis considered the setting of the Chinese health care system. Only direct medical costs, including the costs of EGFR mutation testing, first and second-line chemotherapies (including prescription, preparation, and administration), concomitant medications during therapy, management of treatment-related SAEs, and routine follow-up and laboratory testing (Table 3), were included in the model. 
Icotinib at a dose of $375 \mathrm{mg}$ per day or gefitinib at a dose of $250 \mathrm{mg}$ per day was assumed to be administered to patients positive for an EGFR mutation until disease progression [23, 25-27]. Chemotherapy (pemetrexed, 500 $\mathrm{mg} / \mathrm{m}^{2}$ of body surface area (BSA), plus cisplatin, $75 \mathrm{mg} /$ $\mathrm{m}^{2}$ ) was administered every 21 days for four cycles. Because generic pemetrexed was widely used in Chinese clinical practice, we used the cost of generic pemetrexed in the base-case analysis. In the pemetrexed strategy, pemetrexed treatment $\left(500 \mathrm{mg} / \mathrm{m}^{2}\right.$ every 21 days) was continued in patients who did not progress after four cycles of induction [24]. After disease progression, salvage chemotherapy and supportive care were prescribed; in this model, 56.6\% (26\%$72 \%$ ) of patients received salvage treatment regardless of the first-line therapy [24, 38-42]. The costs of utilizing resources related to salvage chemotherapies, management of SAEs, supportive care and palliative care in end-of-life were derived from a previously published study [43]. The costs for management of SAEs from each strategy were calculated as the cumulative probability-weighted average of SAE costs from the first-line control strategy using the following formula: cost of SAEs from the platinum-based chemotherapy per cycle $\times$ cumulative probability of SAEs from the corresponding strategy / cumulative probability of SAEs from the platinum-based chemotherapy [43]. To calculate the dosage of chemotherapeutic agents, we assumed that a typical patient had a weight of $65 \mathrm{~kg}$ and a height of $1.64 \mathrm{~m}$, resulting in a BSA of $1.72 \mathrm{~m}^{2}$. The cost of EGFR mutation testing per patient was provided by the laboratories of local hospitals. The treatment costs were estimated based on a clinical study.

Because of the high costs of icotinib and gefitinib, as well as the limited wealth of patients in China, the icotinib and gefitinib Patient Assistance Program (PAP) was implemented for Chinese patients positive for ALK gene rearrangement. Currently, the PAP requires patients to pay US $\$ 11,538$ for gefitinib and US $\$ 11,077$ for icotinib, after which they receive icotinib and gefitinib for free until disease progression. Therefore, the impact of the PAP was evaluated in scenario analyses.

The utility scores of PFS and survival after progression were obtained from previously published studies (Table 2) $[44,45]$. The reported disutility caused by SAEs was also considered in the current analysis [44].

\section{Sensitivity analyses}

One-way and probabilistic sensitivity analyses were performed to examine the uncertainty in the model. In the one-way sensitivity analyses, relevant parameters were changed one-by-one to their respective upper and lower boundaries in order to explore the sensitivity of the findings to plausible variations in specific data inputs. The results of the one-way sensitivity analyses are presented in a Tornado diagram. The ranges of the parameters used in the one-way sensitivity analyses were obtained from the published literature; when reported data were not available, a range of $\pm 25 \%$ of the base-case value was used (Table 1 and 2). For the probabilistic sensitivity analyses, parameters were sampled using the Monte Carlo method to run 1,000 replicated outcomes. Based on the ISPOR-SMDM Modeling Good Research Practices Task Force report on model parameter estimation and uncertainty [46], the beta distribution was used for incidence rates, risks, probabilities, proportions and utilities; the normal distribution was used for the HR; and the gamma distribution was used for costs (Table 1 and 2). Cost-effectiveness acceptability curves (CEACs) of vaccination versus no vaccination were generated to present the probabilities of cost-effectiveness. Model development and data analysis were performed in the R statistical environment (version 3.3.1; R Development Core Team, Vienna, Austria).

\section{ACKNOWLEDGMENTS}

This study was supported by the Fourth Round of the Three-year Action Plan on the Public Health Discipline and Talent Program (Evidence-based Public Health and Health Economics, No. 15GWZK0901), the Key Discipline and Specialty Foundation of the Shanghai Municipal Commission of Health and Family Planning (No. 2012ZDXK003) and the National Natural Science Foundation of China (No. 71373160). The funding agencies had no role in the study design, data collection or analysis, decision to publish, or preparation of the manuscript. We wish to thank two reviewers and editor very much for your constructive review and many suggestions that helped to improve the final version of the paper considerably and acknowledged this in the manuscript

\section{COMPETING INTEREST}

None of the authors have any personal or financial conflicts of interest.

\section{Author's contributions}

Dr. Shun $\mathrm{Lu}$ and $\mathrm{Wu}$ Bin adapted the model, conducted the analyses, interpreted the results and wrote the manuscript. Dr. Ming Ye, Jie Fu and Shun Lu contributed to data collection and manuscript preparation. Dr. Wu Bin supervised the study, contributed to the interpretation of the results, reviewed the manuscript and is the guarantor of the overall content.

\section{REFERENCES}

1. Soerjomataram I, Lortet-Tieulent J, Parkin DM, Ferlay J, Mathers C, Forman D and Bray F. Global burden of cancer in 2008: a systematic analysis of disability-adjusted lifeyears in 12 world regions. LANCET. 2012; 380:1840-1850. 
2. Chen W, Zheng R, Zeng H, Zhang S and He J. Annual report on status of cancer in China, 2011. Chin J Cancer Res. 2015; 27:2-12.

3. Liu YN, Qi JL, Liu JM, Yin P, Li YC, You JL, Zeng XY, Liu SW, Zhou MG and Wang LJ. Disease burden of lung cancer in the Chinese population, in 1990 and 2013. Zhonghua Liu Xing Bing Xue Za Zhi. 2016; 37:752-757.

4. Felip E, Stahel RA and Pavlidis N. ESMO Minimum Clinical Recommendations for diagnosis, treatment and follow-up of non-small-cell lung cancer (NSCLC). ANN ONCOL. 2005; 16:i28-i29.

5. William WJ, Lin HY, Lee JJ, Lippman SM, Roth JA and Kim ES. Revisiting stage IIIB and IV non-small cell lung cancer: analysis of the surveillance, epidemiology, and end results data. CHEST. 2009; 136:701-709.

6. Zhi X, Shi Y and Yu J. Standards for the diagnosis and treatment of primary lung cancer (2015 version) in China. Zhonghua Zhong Liu Za Zhi. 2015; 37:67-78.

7. Rossi A, Chiodini P, Sun JM, O’Brien ME, von Plessen C, Barata F, Park K, Popat S, Bergman B, Parente B, Gallo C, Gridelli C, Perrone F and Di Maio M. Six versus fewer planned cycles of first-line platinum-based chemotherapy for non-small-cell lung cancer: a systematic review and meta-analysis of individual patient data. LANCET ONCOL. 2014; 15:1254-1262.

8. Ellis PM, Coakley N, Feld R, Kuruvilla S and Ung YC. Use of the epidermal growth factor receptor inhibitors gefitinib, erlotinib, afatinib, dacomitinib, and icotinib in the treatment of non-small-cell lung cancer: a systematic review. CURR ONCOL. 2015; 22:e183-e215.

9. Liang W, Wu X, Fang W, Zhao Y, Yang Y, Hu Z, Xue C, Zhang J, Zhang J, Ma Y, Zhou T, Yan Y, Hou X, Qin T, Dinglin $X$ and Tian Y, et al. Network meta-analysis of erlotinib, gefitinib, afatinib and icotinib in patients with advanced non-small-cell lung cancer harboring EGFR mutations. PLOS ONE. 2014; 9:e85245.

10. Ettinger DS, Wood DE, Akerley W, Bazhenova LA, Borghaei H, Camidge DR, Cheney RT, Chirieac LR, D'Amico TA, Demmy TL, Dilling TJ, Govindan R, Grannis FJ, Horn L, Jahan TM and Komaki R, et al. Non-small cell lung cancer, version 1.2015. J Natl Compr Canc Netw. 2014; 12:1738-1761.

11. Liang W, Wu X, Fang W, Zhao Y, Yang Y, Hu Z, Xue C, Zhang J, Zhang J, Ma Y, Zhou T, Yan Y, Hou X, Qin T, Dinglin $\mathrm{X}$ and Tian Y, et al. Network meta-analysis of erlotinib, gefitinib, afatinib and icotinib in patients with advanced non-small-cell lung cancer harboring EGFR mutations. PLOS ONE. 2014; 9:e85245.

12. Shi Y, Sun Y, Ding C, Wang Z, Wang C, Bai C, Bai C, Feng J, Liu X, Li F, Yang Y, Shu Y, Wu M, He J, Zhang Y and Zhang S, et al. China Experts Consensus on Icotinib for Non-small Cell Lung Cancer Treatment(2016 version). Zhongguo Fei Ai Za Zhi. 2016; 19:489-494.

13. Ni J and Zhang L. Evaluation of Three Small Molecular Drugs for Targeted Therapy to Treat Nonsmall Cell Lung Cancer. Chin Med J (Engl). 2016; 129:332-340.
14. Chouaid C, Crequit P, Borget I and Vergnenegre A. Economic evaluation of first-line and maintenance treatments for advanced non-small cell lung cancer: a systematic review. Clinicoecon Outcomes Res. 2015; 7:9-15.

15. Narita Y, Matsushima Y, Shiroiwa T, Chiba K, Nakanishi Y, Kurokawa $\mathrm{T}$ and Urushihara H. Cost-effectiveness analysis of EGFR mutation testing and gefitinib as first-line therapy for non-small cell lung cancer. LUNG CANCER. 2015; 90:71-77.

16. Lim EA, Lee H, Bae E, Lim J, Shin YK and Choi SE. Economic Evaluation of Companion Diagnostic Testing for EGFR Mutations and First-Line Targeted Therapy in Advanced Non-Small Cell Lung Cancer Patients in South Korea. PLOS ONE. 2016; 11:e160155.

17. de Lima LGJ, Segel JE, Tan DS, Do YK, Mok T and Finkelstein EA. Cost-effectiveness of epidermal growth factor receptor mutation testing and first-line treatment with gefitinib for patients with advanced adenocarcinoma of the lung. CANCER-AM CANCER SOC. 2012; 118:1032-1039.

18. Zhang C, Zhang H, Shi J, Wang D, Zhang X, Yang J, Zhai $\mathrm{Q}$ and Ma A. Trial-Based Cost-Utility Analysis of Icotinib versus Gefitinib as Second-Line Therapy for Advanced Non-Small Cell Lung Cancer in China. PLOS ONE. 2016; 11:e151846.

19. Rosell R, Carcereny E, Gervais R, Vergnenegre A, Massuti B, Felip E, Palmero R, Garcia-Gomez R, Pallares C, Sanchez JM, Porta R, Cobo M, Garrido P, Longo F, Moran $\mathrm{T}$ and Insa A, et al. Erlotinib versus standard chemotherapy as first-line treatment for European patients with advanced EGFR mutation-positive non-small-cell lung cancer (EURTAC): a multicentre, open-label, randomised phase 3 trial. LANCET ONCOL. 2012; 13:239-246.

20. De Greve J, Van Meerbeeck J, Vansteenkiste JF, Decoster L, Meert AP, Vuylsteke P, Focan C, Canon JL, Humblet Y, Berchem G, Colinet B, Galdermans D, Bosquee L, Vermeij J, Dewaele A and Geers C, et al. Prospective Evaluation of First-Line Erlotinib in Advanced Non-Small Cell Lung Cancer (NSCLC) Carrying an Activating EGFR Mutation: A Multicenter Academic Phase II Study in Caucasian Patients (FIELT). PLOS ONE. 2016; 11:e147599.

21. Takeda M, Okamoto I, Yamanaka T, Nakagawa $\mathrm{K}$ and Nakanishi Y. Impact of treatment with bevacizumab beyond disease progression: a randomized phase II study of docetaxel with or without bevacizumab after platinumbased chemotherapy plus bevacizumab in patients with advanced nonsquamous non-small cell lung cancer (WJOG 5910L). BMC CANCER. 2012; 12:327.

22. Li SH, Hsieh MH and Fang YF. Afatinib in Treatment-Naive Patients With EGFR-Mutated Lung Adenocarcinoma With Brain Metastasis: A Case Series. Medicine (Baltimore). 2015; 94:e1739.

23. Shi Y, Wang L, Han B, Li W, Yu P, Liu Y, Ding C, Song X, Ma Z, Ren X, Feng J, Zhang H, Chen G, Wu N, Han $\mathrm{X}$ and Yao C, et al. First-Line Icotinib Versus Cisplatine/ 
Pemetrexed Plus Pemetrexed Maintenance in Advanced NSCLC Patients with EGFR Mutation. J THORAC ONCOL. 2015; 102:S205-S206.

24. Paz-Ares L, de Marinis F, Dediu M, Thomas M, Pujol JL, Bidoli P, Molinier O, Sahoo TP, Laack E, Reck M, Corral J, Melemed S, John W, Chouaki N, Zimmermann AH and Visseren-Grul C, et al. Maintenance therapy with pemetrexed plus best supportive care versus placebo plus best supportive care after induction therapy with pemetrexed plus cisplatin for advanced non-squamous non-small-cell lung cancer (PARAMOUNT): a double-blind, phase 3, randomised controlled trial. LANCET ONCOL. 2012; 13:247-255.

25. Mitsudomi T, Morita S, Yatabe Y, Negoro S, Okamoto I, Tsurutani J, Seto T, Satouchi M, Tada H, Hirashima T, Asami K, Katakami N, Takada M, Yoshioka H, Shibata K and Kudoh S, et al. Gefitinib versus cisplatin plus docetaxel in patients with non-small-cell lung cancer harbouring mutations of the epidermal growth factor receptor (WJTOG3405): an open label, randomised phase 3 trial. LANCET ONCOL. 2010; 11:121-128.

26. Mok TS, Wu YL, Thongprasert S, Yang CH, Chu DT, Saijo N, Sunpaweravong P, Han B, Margono B, Ichinose Y, Nishiwaki Y, Ohe Y, Yang JJ, Chewaskulyong B, Jiang $\mathrm{H}$ and Duffield EL, et al. Gefitinib or carboplatin-paclitaxel in pulmonary adenocarcinoma. N Engl J Med. 2009; 361:947-957.

27. Maemondo M, Inoue A, Kobayashi K, Sugawara S, Oizumi $\mathrm{S}$, Isobe $\mathrm{H}$, Gemma A, Harada M, Yoshizawa H, Kinoshita I, Fujita Y, Okinaga S, Hirano H, Yoshimori K, Harada T and Ogura T, et al. Gefitinib or chemotherapy for non-smallcell lung cancer with mutated EGFR. N Engl J Med. 2010; 362:2380-2388.

28. Xiao HQ, Tian RH, Zhang ZH, Du KQ and Ni YM. Efficacy of pemetrexed plus platinum doublet chemotherapy as firstline treatment for advanced nonsquamous non-small-celllung cancer: a systematic review and meta-analysis. Onco Targets Ther. 2016; 9:1471-1476.

29. Wu B, Li T, Cai J, Xu Y and Zhao G. Cost-effectiveness analysis of adjuvant chemotherapies in patients presenting with gastric cancer after D2 gastrectomy. BMC CANCER. 2014; $14: 984$.

30. Hoyle M, Green C, Thompson-Coon J, Liu Z, Welch K, Moxham $T$ and Stein K. Cost-effectiveness of temsirolimus for first line treatment of advanced renal cell carcinoma. VALUE HEALTH. 2010; 13:61-68.

31. Woods BS, Hawkins N and Scott DA. Network metaanalysis on the log-hazard scale, combining count and hazard ratio statistics accounting for multi-arm trials: a tutorial. BMC MED RES METHODOL. 2010; 10:54.

32. Higgins JP, Jackson D, Barrett JK, Lu G, Ades AE and White IR. Consistency and inconsistency in network metaanalysis: concepts and models for multi-arm studies. Res Synth Methods. 2012; 3:98-110.

33. Hayashi H, Okamoto I, Morita S, Taguri M and Nakagawa K. Postprogression survival for first-line chemotherapy of patients with advanced non-small-cell lung cancer. ANN ONCOL. 2012; 23:1537-1541.

34. Midha A, Dearden S and McCormack R. EGFR mutation incidence in non-small-cell lung cancer of adenocarcinoma histology: a systematic review and global map by ethnicity (mutMapII). AM J CANCER RES. 2015; 5:2892-2911.

35. Solomon BJ, Mok T, Kim DW, Wu YL, Nakagawa K, Mekhail T, Felip E, Cappuzzo F, Paolini J, Usari T, Iyer $\mathrm{S}$, Reisman A, Wilner KD, Tursi J and Blackhall F. Firstline crizotinib versus chemotherapy in ALK-positive lung cancer. N Engl J Med. 2014; 371:2167-2177.

36. Shi Y, Zhang L, Liu X, Zhou C, Zhang L, Zhang S, Wang D, Li Q, Qin S, Hu C, Zhang Y, Chen J, Cheng Y, Feng $\mathrm{J}$, Zhang $\mathrm{H}$ and Song $\mathrm{Y}$, et al. Icotinib versus gefitinib in previously treated advanced non-small-cell lung cancer (ICOGEN): a randomised, double-blind phase 3 noninferiority trial. LANCET ONCOL. 2013; 14:953-961.

37. Wu B, Chen H, Shen J and Ye M. Cost-effectiveness of adding rh-endostatin to first-line chemotherapy in patients with advanced non-small-cell lung cancer in China. CLIN THER. 2011; 33:1446-1455.

38. Sandler A, Gray R, Perry MC, Brahmer J, Schiller JH, Dowlati A, Lilenbaum R and Johnson DH. Paclitaxelcarboplatin alone or with bevacizumab for non-small-cell lung cancer. N Engl J Med. 2006; 355:2542-2550.

39. Pirker R, Pereira JR, Szczesna A, von Pawel J, Krzakowski M, Ramlau R, Vynnychenko I, Park K, Yu CT, Ganul V, Roh JK, Bajetta E, O'Byrne K, de Marinis F, Eberhardt W and Goddemeier $\mathrm{T}$, et al. Cetuximab plus chemotherapy in patients with advanced non-small-cell lung cancer (FLEX): an open-label randomised phase III trial. LANCET. 2009; 373:1525-1531.

40. Cappuzzo F, Ciuleanu T, Stelmakh L, Cicenas S, Szczesna A, Juhasz E, Esteban E, Molinier O, Brugger W, Melezinek I, Klingelschmitt G, Klughammer B and Giaccone G. Erlotinib as maintenance treatment in advanced non-smallcell lung cancer: a multicentre, randomised, placebocontrolled phase 3 study. LANCET ONCOL. 2010; 11:521-529.

41. Zhang X, Zang J, Xu J, Bai C, Qin Y, Liu K, Wu C, Wu M, He Q, Zhang S, Wei L and He J. Maintenance therapy with continuous or switch strategy in advanced non-small cell lung cancer: a systematic review and meta-analysis. CHEST. 2011; 140:117-126.

42. Ciuleanu T, Brodowicz T, Zielinski C, Kim JH, Krzakowski M, Laack E, Wu YL, Bover I, Begbie S, Tzekova V, Cucevic B, Pereira JR, Yang SH, Madhavan J, Sugarman $\mathrm{KP}$ and Peterson P, et al. Maintenance pemetrexed plus best supportive care versus placebo plus best supportive care for non-small-cell lung cancer: a randomised, double-blind, phase 3 study. LANCET. 2009; 374:1432-1440.

43. Lu S, Zhang J, Ye M, Wang B and Wu B. Economic analysis of ALK testing and crizotinib therapy for advanced nonsmall-cell lung cancer. PHARMACOGENOMICS. 2016; 17:985-994. 
44. Grutters JP, Joore MA, Wiegman EM, Langendijk JA, de Ruysscher D, Hochstenbag M, Botterweck A, Lambin P and Pijls-Johannesma M. Health-related quality of life in patients surviving non-small cell lung cancer. THORAX. 2010; 65:903-907.

45. Chouaid C, Agulnik J, Goker E, Herder GJ, Lester JF, Vansteenkiste J, Finnern HW, Lungershausen J, Eriksson J, Kim K and Mitchell PL. Health-related quality of life and utility in patients with advanced non-small-cell lung cancer: a prospective cross-sectional patient survey in a real-world setting. J THORAC ONCOL. 2013; 8:997-1003.

46. Briggs AH, Weinstein MC, Fenwick EAL, Karnon J, Sculpher MJ, Paltiel AD and ISPOR-SMDM MGRP. Model parameter estimation and uncertainty analysis: a report of the ISPOR-SMDM Modeling Good Research Practices Task Force Working Group-6. Medical Decision Making. 2012; 32:722-732. 